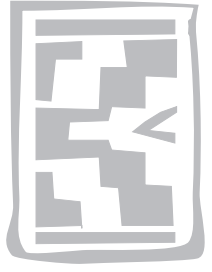

\title{
Prevalence of serotype specific antibody to equine encephalosis virus in Thoroughbred yearlings in South Africa (1999-2004)
}

\author{
P.G. HOWELL ${ }^{\dagger}$, JANE P. NURTON, DALEEN NEL, CARINA W. LOURENS and A.J. GUTHRIE* \\ Equine Research Centre, Faculty of Veterinary Science, University of Pretoria, Private Bag X04, \\ Onderstepoort, 0110 South Africa
}

\begin{abstract}
HOWELL, P.G., NURTON, JANE P., NEL, DALEEN, LOURENS, CARINA W. \& GUTHRIE, A.J. 2008. Prevalence of serotype specific antibody to equine encephalosis virus in Thoroughbred yearlings in South Africa (1999-2004). Onderstepoort Journal of Veterinary Research, 75:153-161

Cohorts of yearlings were sampled over a period of 6 years in a retrospective serological survey to establish the annual prevalence of serotype specific antibody to equine encephalosis virus on Thoroughbred stud farms distributed within defined geographical regions of South Africa.

Seasonal seroprevalence varied between $3.6 \%$ and $34.7 \%$, revealing both single and multiple serotype infections in an individual yearling. During the course of this study serotypes 1 and 6 were most frequently and extensively identified while the remaining serotypes 2, 3, 4, 5 and 7 were all identified as sporadic and localized infections affecting only individual horses.
\end{abstract}

This study of the seasonal prevalence of equine encephalosis virus has a corollary and serves as a useful model in the seasonal incidence of the serotypes of African horse sickness and bluetongue in regions where the respective diseases are endemic.

Keywords: Equine encephalosis virus, horses, neutralizing antibody, orbivirus, prevalence, seroepidemiology, serotypes

\section{INTRODUCTION}

Equine encephalosis virus (EEV) is classified in the genus Orbivirus of the family Reoviridae (Verwoerd, Huismans \& Erasmus 1979). In southern Africa three orbiviruses transmitted by Culicoides spp. have been identified as real or potential pathogens of domestic animals, namely bluetongue virus (BTV) in ruminants and African horse sickness virus (AHSV) and EEV in equids. The genome of each of these viruses

* Author to whom correspondence is to be directed. E-mail: alan.guthrie@up.ac.za

† Present address: 384 Amberglen, P.O. Box X004, Howick, 3290, South Africa

Accepted for publication 21 April 2008-Editor consists of ten dsRNA segments that encode seven structural and three non-structural proteins (Verwoerd \& Huismans 1972; Huismans 1979). Genome segment 2 encodes VP2 which is one of two outer capsid proteins and determines serotype-specificity and also serves as the dominant antigen inducing protective immunity (Huismans, Van der Walt, Cloete \& Erasmus 1987; Scanlen, Paweska, Verschoor \& Van Dijk 2002). Gorman, Taylor \& Walker (1983) reviewed the genetic relationships of the orbiviruses and drew attention to the complexity of antigenic variation within each serological group. Studies on the natural occurrence of AHSV (Mclntosh 1958; Howell 1962), BTV (Howell 1969) and more recently of EEV (Erasmus, Boshoff \& Pieterse 1996; Howell, Groenewald, Visage, Bosman, Coetzer \& Guthrie 
2002) have identified by serum-virus neutralization (SVN), the existence of multiple serotypes within each serogroup in southern Africa. This multiplicity of serotypes amongst these three viruses, within the endemic regions of southern Africa has a profound influence on the epidemiology of these infections.

The persistence of the individual serotypes of these viruses, when vector populations are inactive or appear to be absent on account of low winter temperatures or dry climatic periods is an important determinant in their regional distribution. Meiswinkel, Nevill \& Venter (1994) noted that there was as yet no evidence that these viruses were transmitted transovarially in Culicoides spp., while Du Toit (1962) and Nevill (1971) were of the opinion that in the case of BTV, vertebrate reservoir hosts such as cattle, which exhibit inapparent infections, were necessary to bridge the winter months. Where AHSV and EEV are concerned, donkeys and zebras in warm, lowlying areas where Culicoides are active throughout the year may fulfil a role similar to that of cattle for BTV (Nevill 1971; Barnard 1993). The onset of summer with more favourable environmental conditions, in particular higher temperatures and precipitation, will promote the emergence of greater numbers of Culicoides, higher infection rates and older individuals in the population, all of which will increase the level of transmission. The further spread of the individual serotypes during the summer months occurs by either dispersal of infected competent species of Culicoides or the translocation of viraemic vertebrate hosts.

Donkeys and free-living zebras have been monitored for the presence of group specific antibody to AHSV and EEV (Paweska, Gerdes, Woods \& Williams 1999; Venter, Paweska, Williams \& Nevill 1999). These surveys confirmed the high prevalence of positive sera from unvaccinated donkeys for both AHSV and EEV and established a distribution pattern for these infections. In 1993 Barnard \& Paweska reported the identification of antibody against individual serotypes of EEV in a cohort of zebras confined to the Kruger National Park in which neutralising antibody to seven serotypes of EEV was identified. In all these studies, however, the susceptible status of the donors and the time of infection were not established. A similar shortcoming prevailed in a retrospective survey conducted amongst groups of Thoroughbred mares whose ages were not established at the time of sampling, but whose sera showed a high prevalence of virus neutralizing antibody to one or more of the seven validated serotypes of EEV. In this study (Howell et al. 2002), the locality or time at which the infections took place were not established.

The substantial adverse economic consequences of bluetongue (BT) and African horse sickness (AHS) require annual polyvalent prophylactic immunization. In terms of the response to individual serotypes included in the polyvalent vaccines the resulting immunity in individual animals is variable. Serotype specific antibody derived from immunization, natural challenge or the transfer of colostrum cannot be distinguished by conventional SVN assays, thus sero-epidemiological surveys are inconclusive in establishing seroconversion to natural challenge and obscure the regional prevalence of the serotypes of BTV and AHSV in their hosts.

Within the endemic regions, unpredictable seasonal epidemics of AHS may occur, during the course of which, numerous different serotypes may be recovered from blood or tissue samples taken from clinically affected horses. These isolates, however, represent only a small sample and do not reflect the actual prevalence of the individual serotypes. A more reliable approach to resolve this shortcoming is the demonstration of seroconversion in unvaccinated animals to natural challenge.

The epidemiology of EEV would appear in many respects to be similar to that of AHSV and BTV, thus this usually benign infection in equids may be considered as a model for the study of the distribution and seasonal appearance of the multiple serotypes of all three orbiviruses. Equine encephalosis generally has minor economic implications and no vaccine has been developed, thus the high seroprevalence is uncomplicated by antibody derived from prophylactic immunization. On account of the generally mild clinical signs and ephemeral character of the disease the majority of infections pass unnoticed and the collection of samples for serological surveys to detect serotype specific seroconversion is unbiased.

The objective of this retrospective serological investigation was to establish the annual occurrence of the individual serotypes of EEV and their distribution and prevalence within cluster groups of horses on stud farms within defined geographical regions. The monitoring of the successful transmission of individual serotypes would provide some indication of the origin and character of the endemic cycles of infection exhibited by EEV during the mid- to late summers included in the study period. 


\section{MATERIALS AND METHODS}

Approximately 3200 (Range 3111-3329) Thoroughbred foals were registered with the National Horseracing Authority of Southern Africa from each of the foaling seasons (August to December) from 1997 to 2002 in South Africa. Of these registered foals, approximately $500(15 \%)$, were subsequently consigned to the 1999 to 2004 National Yearling Sale (NYS) when they were about 18 months old (Table 1). The respective groups of yearlings evaluated in this study are referred to as the 1999-2004 yearling crops. Mares typically foaled in foaling boxes and were moved to pastures within $48 \mathrm{~h}$ of foaling. Weanlings and yearlings were reared on pasture. Yearlings were stabled for up to 2 months prior to the NYS. Midge control was not practised on the farms. Most mares and foals, however, were treated weekly with pyrethroids to prevent tick infestations. Foals generally remained on the farm where they were born until sold at the NYS, except when their dams were sent for breeding (September to December).

\section{Blood collection}

Blood was collected by jugular venipuncture into vacuum tubes without anticoagulant from each of the yearlings consigned to the NYS from 1999 to 2004. The samples were held overnight at $10^{\circ} \mathrm{C}$. After separation of the clot the serum was dispensed into vials, indexed and stored at $-20^{\circ} \mathrm{C}$ until required for serological tests.

\section{Enzyme-linked immunosorbent assay of antibody}

A 1:5 stock dilution of all the serum samples was assayed for group specific antibody to EEV. A competitive ELISA (cELISA) technique, using an extracted serotype 1 EEV antigen as described and validated by Crafford (2001) was used. The percentage inhibition (PI) based on the inclusion of appropriate controls were obtained after the addition of an orthophenylene diamine $/ \mathrm{H}_{2} \mathrm{O}_{2}$ substrate. The reaction was terminated by the addition of $1 \mathrm{M} \mathrm{H}_{2} \mathrm{SO}_{4}$ and the intensity of the colour reaction recorded using a $492 \mathrm{~nm}$ filter. Samples exhibiting inhibition of $<40 \%$ were set aside and excluded from further examination.

\section{Assay of serum neutralising antibody}

Assays of serotype specific SVN antibody in the stored serum samples which had a $\mathrm{PI}>40 \%$ were performed in a microtitre system, as described previously (Howell et al. 2002). Twofold dilutions (initial dilution of 1:10) of each serum were incubated with approximately $100 \mathrm{TCID}_{50} / 100 \mu$ of each reference antigen which was added in equal volume to the serum dilutions. After incubation at $37.5^{\circ} \mathrm{C}$ in a $5 \%$ $\mathrm{CO}_{2}$ gassed incubator, a Vero cell suspension of 480000 cells per $\mathrm{m} \ell$ was added in a volume of $80 \mu \ell$. The progress of the cytopathic effect of the virus was recorded daily. The serum dilution end-points were determined on the development of $50 \%$ destruction of the monolayers inoculated with the dilution of the back titration of the virus representing $100 \mathrm{TCID}_{50}$. The concentration of virus used for the assay of each batch of sera was monitored and where the concentration of virus fell within the range of 30-300 $\mathrm{TCID}_{50}$, the assay of antibody was accepted. Whilst a serum neutralization titre of $\geq 10$ was considered positive, a titre of $\geq 80$ was interpreted as confirmation of an unambiguous response to infection with the specific serotype of EEV.

\section{Statistical analysis}

Relative risks (RR) were used to quantify the relationships between risk factors and seroprevalence, respectively, between four age groups of the yearlings included in this study.

\section{RESULTS}

\section{Interpretation of serological tests}

At a serum dilution of 1:5 the cELISA identified 680 positive sera with $95 \%$ of the samples exceeding a $\mathrm{PI}$ of $60 \%$.

TABLE 1 Summary of size of foal crop, number and percentage of yearlings sampled at the 1999-2004 National Yearling Sales

\begin{tabular}{|l|l|l|l|}
\hline Year of sampling & Size of crop & Yearlings sampled & Percentage of crop sampled \\
\hline 1999 & 3189 & 516 & 16.2 \\
2000 & 3207 & 513 & 16.0 \\
2001 & 3329 & 483 & 14.5 \\
2002 & 3228 & 481 & 14.9 \\
2003 & 3178 & 500 & 15.7 \\
2004 & 3111 & 499 & 16.0 \\
\hline
\end{tabular}


Equine encephalosis virus in Thoroughbred yearlings in South Africa (1999-2004)

TABLE 2 Influence of age on susceptibility to natural EEV challenge

\begin{tabular}{|l|r|l|l|l|}
\hline Month of birth & Foals & Seropositive & Percent & Relative risk (RR) \\
\hline August & 442 & 118 & 0.27 & 1.35 \\
September & 1022 & 245 & 0.24 & 1.21 \\
October & 1037 & 205 & 0.20 & 1.00 \\
November/December & 491 & 112 & 0.23 & 1.15 \\
\hline
\end{tabular}

TABLE 3 Prevalence of primary and multiple serotype infection of yearlings

\begin{tabular}{|c|c|c|c|c|c|c|}
\hline \multirow{3}{*}{ Yearling crop } & \multirow{3}{*}{$\begin{array}{l}\text { Yearlings } \\
\text { sampled }\end{array}$} & \multirow{3}{*}{$\begin{array}{l}\text { Seropositive } \\
\text { yearlings }\end{array}$} & \multirow{3}{*}{$\begin{array}{l}\text { Percentage } \\
\text { seropositive }\end{array}$} & \multicolumn{3}{|c|}{ Seropositive yearlings } \\
\hline & & & & \multirow{2}{*}{$\begin{array}{l}\text { Single } \\
\text { serotype } \\
\text { infections }\end{array}$} & \multicolumn{2}{|c|}{ Multiple infections } \\
\hline & & & & & Individuals & Immune profile \\
\hline 1999 & 516 & 148 & 28.7 & 148 & 0 & - \\
\hline 2000 & 513 & 90 & 17.5 & 87 & $\begin{array}{l}1 \\
1 \\
1\end{array}$ & $\begin{array}{l}\text { EEV1, EEV5 } \\
\text { EEV1, EEV6 } \\
\text { EEV1, EEV7 }\end{array}$ \\
\hline 2001 & 483 & 146 & 30.2 & 142 & 4 & EEV1, EEV7 \\
\hline 2002 & 481 & 167 & 34.7 & 165 & 2 & EEV1, EEV6 \\
\hline 2003 & 500 & 111 & 22.2 & 94 & $\begin{array}{l}9 \\
1 \\
6 \\
1\end{array}$ & $\begin{array}{l}\text { EEV1, EEV6 } \\
\text { EEV1, EEV7 } \\
\text { EEV6, EEV7 } \\
\text { EEV4, EEV6 }\end{array}$ \\
\hline 2004 & 499 & 18 & 3.6 & 14 & $\begin{array}{l}1 \\
1 \\
1 \\
1\end{array}$ & $\begin{array}{l}\text { EEV1, EEV6 } \\
\text { EEV6, EEV4, } \\
\text { EEV6, EEV7 } \\
\text { EEV1, EEV3, EEV7 }\end{array}$ \\
\hline
\end{tabular}

\begin{tabular}{|l|l|l|}
\hline Year 1 & Year 2 & Year 3 \\
\hline
\end{tabular}

Challenge Challenge
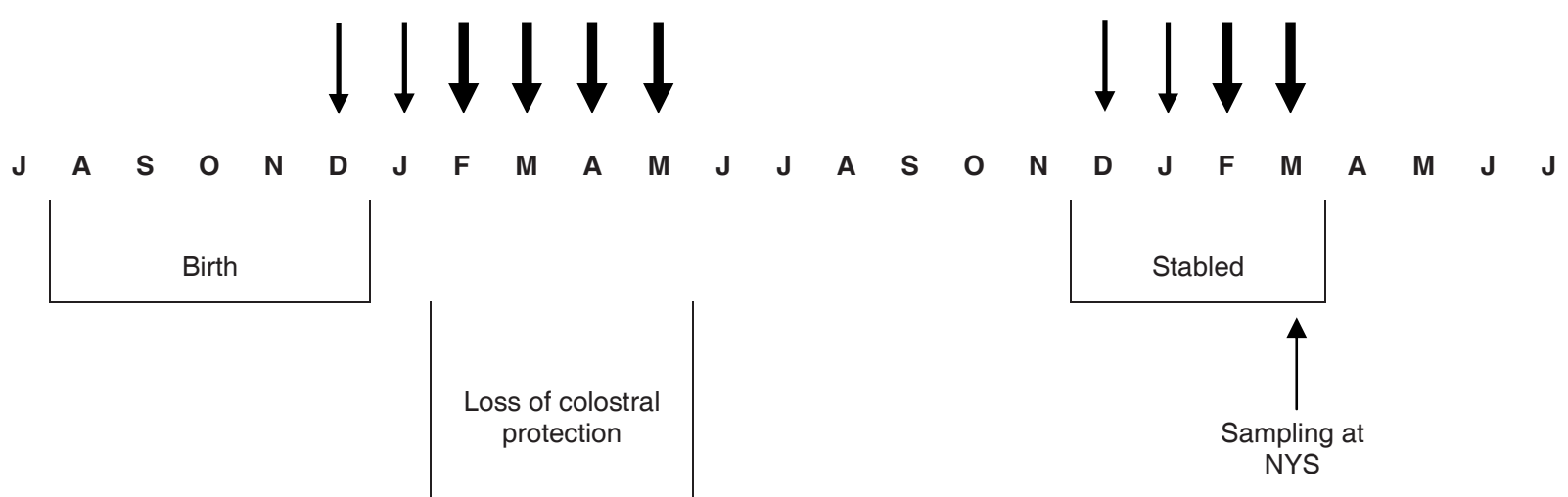

FIG. 1 Seasonal exposure of the horse population to the transmission of equine encephalosis virus in South Africa prior to the National Yearling Sales 

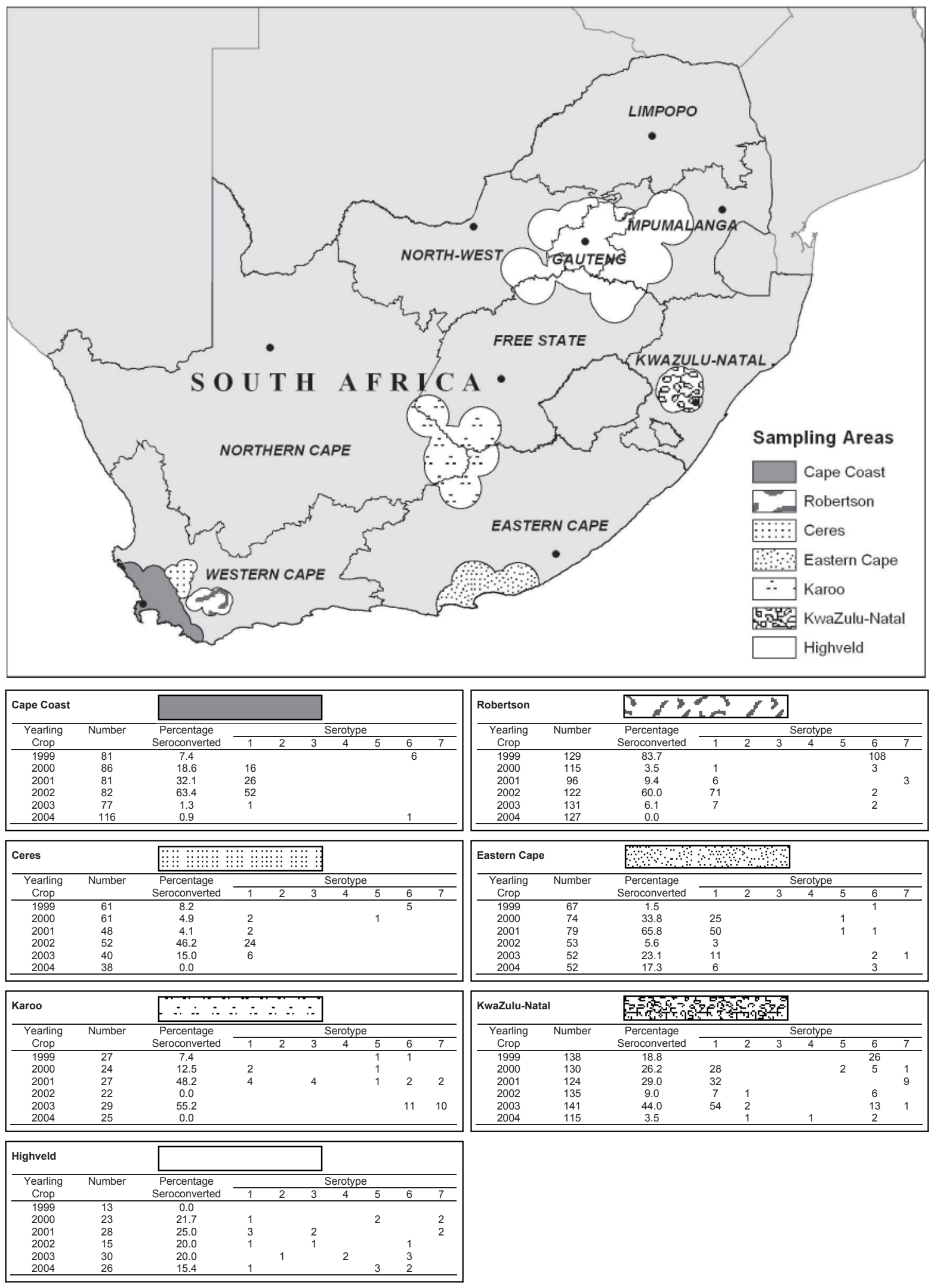

FIG. 2 Distribution of stud farms included in the survey with numbers of yearlings sampled per year, percentage of yearlings seropositive for equine encephalosis virus and numbers of yearlings positive for type specific antibody for each of the seven recognised serotypes of equine encephalosis virus for each of the years investigated (1999-2004) 
Yearlings which appeared to have been exposed to a single serotype, invariably had SVN antibody titres of $1: 240$ to $>1: 320$ to the homologous antigen. Eighteen horses $(0.6 \%)$ were identified in the latter years of the survey which exhibited high PI (80\%) by cELISA but low SVN end-points. These horses were considered to have been recently infected in the period immediately preceding their shipment to the NYS and were excluded from the distribution map, as they did not fulfil the required criteria of an unambiguous response to natural infection. As a retrospective study, a second serum sample to confirm a rising antibody titre in these horses was not available for examination.

\section{Influence of age on susceptibility to infection}

An analysis of the percentage of seropositive yearlings, classed according to the month in which they were born (August to November/December over the 6 years of the survey) is given in Table 2.

The relative risk of infection (RR) during the following summer showed no significant difference between foals born in August in which colostral protection would have waned and those born in November/ December, when maternal antibody may have been expected to provide some measure of protection against natural infection (see Fig. 1).

\section{Seasonal serconversion to EEV}

A summary of the primary and multiple infections that took place in each cohort of yearlings is given in Table 3. These data confirm the variable annual seroprevalence of EEV. In the 1999, 2001 and 2002 yearling crops the seroprevalence varied from $28.7 \%$ to $34.7 \%$ of the population sampled, whereas in 2004 the seroprevalence was only $3.6 \%$.

Notwithstanding the relatively short period of exposure, 30 yearlings were infected with more than one serotype. The profile of these multiple infections invariably included the predominant serotype in the region and a random assortment of one or other additional heterologous serotype.

\section{Distribution of serotypes of EEV}

A distribution map with an analysis of the serotypes identified in each cluster during the 6 years covered by this survey is presented in Fig. 2. The insert for each cluster indicates the year of sampling, bearing in mind that infection took place during the previous summer, the number of yearlings sampled, those that seroconverted and the percentage prevalence of EEV. The number of positive sera is occasionally at variance with the prevalence of individual serotypes due to the detection of antibody to more than one serotype in individual horses. Although all of South Africa's stud farms were not represented at the NYS, the sample is, however, representative of the main Thoroughbred breeding regions of the country. Although each cluster was located in a region of common topography and climate, no attempt was made to associate these environmental conditions and their influence on the vector population with the seasonal variations in the prevalence of the serotypes within the region or on individual farms. Apart from recognizing the primary role of the vector in the transmission of each serotype, the dynamics of the Culicoides populations within the terrain of each cluster requires further study.

During the 6-year duration of this survey, serotypes 1 and 6 were predominant and account for $65 \%$ and $30 \%$, respectively, of the recorded seroconversions. Serotype 7 represented by the isolate $21 / 20$, the most recently identified serotype recovered in 2000 , was detected in only $4.5 \%$ of the samples. Antibody homologous to the remaining serotypes namely 2 , 3,4 and 5 was only sporadically identified, except within the KwaZulu-Natal cluster where serotypes 2, 4 and 5 were identified during different seasons in the 6-year period of sampling. Serotype 2 was identified on two separate stud farms $70 \mathrm{~km}$ apart on the Highveld during the 2000 seasonal infection and during the same season in the sera of four yearlings included in the Karoo cluster. The two stud farms on which these yearlings were infected were separated by approximately $400 \mathrm{~km}$ from the Highveld cluster, and were situated in a distinct ecological environment, on the banks of a major river system.

An evaluation of the seasonal prevalence of the two dominant serotypes suggests a possible pattern. It would appear that a season or two of high prevalence is followed, in the same cluster, by a dramatic reduction of homologous seroconversion in the following year. This was evident with serotype 1 in the 2001 season in KwaZulu-Natal and Eastern Cape and in the 2002 season in the Robertson and Ceres clusters.

A similar seasonal reduction of infection was observed with serotype 6 in KwaZulu-Natal and Robertson in 1999. Of note in relation to the high prevalence of serotype 6 in the southern clusters, during the 1998 and 2001 seasons, is the absence of any seroconversion to serotype 1 in the yearlings in the remaining clusters. 


\section{DISCUSSION}

The data obtained from this study have provided some insight into the complexity of the epidemiology of EEV infections in an endemic area, where a multiplicity of serotypes have circulated. The unique susceptibility of the yearling population has provided an opportunity to follow successive annual cycles of transmission of EEV between vector and host, in the absence of any complicating previous immunological stimulation. Over a period of 6 years the monitoring of successive groups of yearlings has confirmed the ongoing transmission of the seven serotypes of EEV currently identified in South Africa.

A schematic representation of the complex interrelationship between the age of the horse, colostral protection and the onset and termination of the transmission of the serotypes of EEV is illustrated in Fig. 1. The climatological and ecological factors which determine the magnitude of the vector population are operative well before the onset of transmission in midsummer. Within the transmission cycle the highest prevalence of infection in the yearlings is most likely to occur between February and May during their second year, while the stabling of the yearlings in the months preceding the sales in March of the following year would reduce the risk of exposure. It would therefore appear that the antibody profile detected in individual yearlings sampled in March is a reflection of the prevalence of a particular serotype transmitted during the preceding season.

The decline in the concentration of serotype specific, passively transferred colostral antibody after birth, will determine the susceptibility of the foal to the seasonal transmission of the homologous virus during mid- to late summer. Unpublished data have shown that antibody to specific serotypes of EEV, homologous with the variable profile identified in the serum of the mare at parturition, may be detected in the serum of the foal, for 3-5 months after birth and only occasionally in individuals for a period not exceeding 6 months. No data are, however, available to establish the protective value of the diminishing low concentrations of antibody to homologous challenge, during the mid- to late summer period.

In a separate study conducted on the 1997 cohort of yearlings (Guthrie, Howell, Gardner, Swanepoel, Nurton, Harper, Pardini, Groenewald, Visage, Hedges, Balasuriya, Cornel \& MacLachlan 2003) it was shown that seroconversion to West Nile virus (WNV) was more frequent in foals born in August (RR 4.7) when compared with those born in Novem- ber and December (RR 1.0). Maternally transferred antibody to the monotypic virus appeared to provide protection to challenge during early summer. In contrast, the highly variable immune status of mares to EEV (Howell et al. 2002) fails to provide the foal with an effective polyvalent immunity to natural challenge from the unpredictable array of serotypes identified in this study. The risk of infection therefore appears to be unaffected by the transfer of colostral antibody.

Two distinct cycles of infection have been identified in this survey. A high prevalence of a single serotype during a particular season as recorded in the KwaZulu-Natal and the Robertson clusters where serotype 6 was involved in yearlings sampled in 1999 , or of serotype 1 , which was dominant in the yearling samples of 2000 from the Robertson and Cape Coast clusters. Unpublished records of the recovery of virus from horses during the 1999 outbreak of AHS in the Western Cape, showed a similar pattern, with AHS serotype 7 and EEV serotype 1 were transmitted concurrently over a period of 8 weeks. This is in marked contrast to the low and sporadic appearance of all seven serotypes of EEV identified in clusters that were separated one from another by spatial distance or physical topographical barriers. At most, only a few yearlings in any one season showed seroconversion to these serotypes, occasionally in successive seasons, but more frequently as isolated infections.

Outer capsid protein VP2 determines EEV serotype. More significant in the epidemiology of the orbiviruses is the role of other viral proteins, which could independently determine the efficacy whereby the serotype replicates, is transmitted and maintained over time in an isolated niche. The seroconversion detected in the serum of a yearling reflects the successful transmission of a specific serotype by a competent vector. It was not possible to establish whether an index case early in the season provided the viraemia to initiate an ongoing cycle of transmission between the vectors and other horses, which would account for the high prevalence of serotype 6 in the Robertson cluster for foals born in the 1999 season. The two distinctive epidemiological patterns, however, raise the question as to whether transmission is determined by the composition and dynamics of the vector population in a given area, or the genetic characteristics of the particular virus strain circulating at that time. The isolated seroconversions are of great significance and raise many unanswered questions with respect to the distribution of the serotypes and their persistence in a given 
locality during the inter-epidemic periods which may encompass one or more years.

It was reported that following the first isolation of EEV serotype 2 (Cascara prototype) in 1967, the examination of a number of serum samples from horses in various parts of South Africa showed a high percentage of the sera with homologous antibody, indicating a widespread prevalence of this serotype during the preceding summer (Erasmus, Adelaar, Smit, Lecatsas \& Toms 1970).

During the course of this survey only five yearlings $(0.7 \%)$, from two separate clusters were shown to have been infected after an interval of 37 years with serotype 2. Similarly, in a recent survey amongst aged brood mares on stud farms it was found that only $1.5 \%$ had been previously exposed to this serotype (Howell et al. 2002). The immune profile of these mares clearly showed that the persistently low prevalence of certain serotypes was not the outcome of immunological pressure within the equine population which limited the transmission of the specific serotype.

The mechanism whereby these sporadic and isolated seroconversions to a particular serotype occur is yet to be established.

Previous experience has shown that equids in the incubation period of infection with AHSV may be transported and subsequently provide an index case for further transmission by hitherto uninfected vectors. This translocation of the virus with other natural movements of equids over time might explain the redistribution of individual serotypes as independent members of the serological group.

The persistence of individual serotypes of EEV that are only sporadically transmitted does not appear to lead to dissemination after infection of individual horses. This is apparent from the low prevalence of seroconversion in the study population and unlike the current strains of EEV serotype 6 and 1, are not capable of initiating large scale transmission. The prevalence of EEV infection has a parallel in the seasonal occurrence of AHSV and BTV, where recovery of individual serotypes follows a similar pattern and suggests that the role of the immune status of the mammalian hosts does not affect the prevalence of the individual serotypes in the vector population. Future investigations into the interaction between vector and virus may characterize the persistence of the serotypes in an isolated locus as a unique manifestation of the complex epidemiology of the orbiviruses in southern Africa.

\section{ACKNOWLEDGEMENTS}

The authors thank the Department of Veterinary Tropical Diseases, Faculty of Veterinary Science, University of Pretoria for providing laboratory facilities and support without which this study would not have been possible and Dr Melvyn Quan for assistance with preparation of figures used in this paper. This study was supported in part by funds donated by The Thoroughbred Horseracing Trust and the South African Horse Import and Export Council.

\section{REFERENCES}

BARNARD, B.J.H. 1993. Circulation of African horsesickness virus in zebra (Equus burchelli) in the Kruger National Park, South Africa, as measured by the prevalence of type specific antibodies. Onderstepoort Journal of Veterinary Research, 60:111-117.

BARNARD, B.J.H. \& PAWESKA, J.T. 1993. Prevalence of antibodies against some equine viruses in zebra (Zebra burchelII) in the Kruger National Park, 1991-1992. Onderstepoort Journal of Veterinary Research, 60:175-179.

CRAFFORD, J.E. 2001. Development and validation of enzymelinked immunosorbent assays for detection of equine encephalosis virus antibody and antigen. M.Sc. thesis, University of Pretoria.

DU TOIT, R.M. 1962. The role played by bovines in the transmission of bluetongue in sheep. Journal of the South African Veterinary Medical Association, 33:483-490.

ERASMUS, B.J., ADELAAR, T.F., SMIT, J.D., LECATSAS, G. \& TOMS, T. 1970. The isolation and characterization of equine encephalosis virus. Bulletin de l'Office International des Épizooties, 74:781-789.

ERASMUS, B.J., BOSHOFF, S.T. \& PIETERSE, L.M. 1996. The isolation and characterization of equine encephalosis and serologically related orbiviruses from horses, in Equine infectious diseases IV, edited by J.T. Bryans \& H. Gerber. Princeton, New Jersey: Veterinary Publications Incorporated.

GORMAN, B.M., TAYLOR, J. \& WALKER, P.J. 1983. Orbivirus, in The Reoviridae, edited by W.K. Joklik. New York: Plenum Press.

GUTHRIE, A.J., HOWELL, P.G., GARDNER, I.A., SWANEPOEL, R.E., NURTON, J.P., HARPER, C.K., PARDINI, A., GROENEWALD, D., VISAGE, C.W., HEDGES, J.F., BALASURIYA, U.B., CORNEL, A.J. \& MACLACHLAN, N.J. 2003. West Nile virus infection of Thoroughbred horses in South Africa (2000-2001). Equine Veterinary Journal, 35:601-605.

HOWELL, P.G. 1962. The isolation and identification of further antigenic types of African horsesickness virus. Onderstepoort Journal of Veterinary Research, 29:139-149.

HOWELL, P.G. 1969. The antigenic classification of strains of bluetongue virus, their significance and use in prophylactic immunization. D.V.Sc thesis, University of Pretoria.

HOWELL, P.G., GROENEWALD, D.M., VISAGE, C.W., BOSMAN, A., COETZER, J.A.W. \& GUTHRIE, A.J. 2002. The classification of seven serotypes of equine encephalosis virus and the prevalence of homologous antibody in horses in South Africa. Onderstepoort Journal of Veterinary Research, 69:79-93. 
HUISMANS, H. 1979. Protein synthesis in bluetongue virusinfected cells. Virology, 92:385-396.

HUISMANS, H., VAN DER WALT, N.T., CLOETE, M. \& ERASMUS, B.J. 1987. Isolation of a capsid protein of bluetongue virus that induces a protective immune response in sheep. Virology, 157:172-179.

MCINTOSH, B.M. 1958. Immunological types of horsesickness virus and their significance in immunization. Onderstepoort Journal of Veterinary Research, 27:465-539.

MEISWINKEL, R., NEVILL, E.M. \& VENTER, G.J. 1994. Vectors: Culicoides spp., in Infectious diseases of livestock with special reference to Southern Africa, edited by J.A.W.Coetzer, G.R.Thomson \& R.C.Tustin. Cape Town: Oxford University Press.

NEVILL, E.M. 1971. Cattle and Culicoides biting midges as possible overwintering hosts of bluetongue virus. Onderstepoort Journal of Veterinary Research, 38:65-71.

PAWESKA, J.T., GERDES, G.H., WOODS, P.S.A. \& WILLIAMS, R. 1999. Equine encephalosis in southern Africa: Current situation, in Equine infectious diseases VIII, edited by U. Wernery, J.F. Wade, J.A. Mumford \& O.R. Kaaden. Newmarket: R \& W Publications (Newmarket) Ltd.

SCANLEN, M., PAWESKA, J.T., VERSCHOOR, J.A. \& VAN DIJK, A.A. 2002. The protective efficacy of a recombinant VP2-based African horsesickness subunit vaccine candidate is determined by adjuvant. Vaccine, 20:1079-1088.

VENTER, G.J., PAWESKA, J.T., WILLIAMS, R. \& NEVILL, E.M. 1999. Prevalence of antibodies against African horse sickness (AHS) and equine encephalosis (EE) virus in donkeys in southern Africa, in Equine infectious diseases VIII, edited by U. Wernery, J.F. Wade, J.A. Mumford \& O.R. Kaaden. Newmarket: R \& W Publications (Newmarket) Ltd.

VERWOERD, D.W. \& HUISMANS, H. 1972. Studies on the in vitro and the in vivo transcription of the bluetongue virus genome. Onderstepoort Journal of Veterinary Research, 39: 185-191.

VERWOERD, D.W., HUISMANS, H. \& ERASMUS, B.J. 1979. Orbiviruses, in Comprehensive virology, edited by H. Fraenkel-Conrat \& R.K. Wagner. New York: Plenum Press. 